\title{
Clinical value and cost saving of therapeutic drug monitoring of infliximab in adult patients with inflammatory bowel disease
}

\author{
Authors: Sashiananthan Ganesananthan ${ }^{\mathrm{A}}$ and Dharmaraj Durai ${ }^{\mathrm{B}}$
}
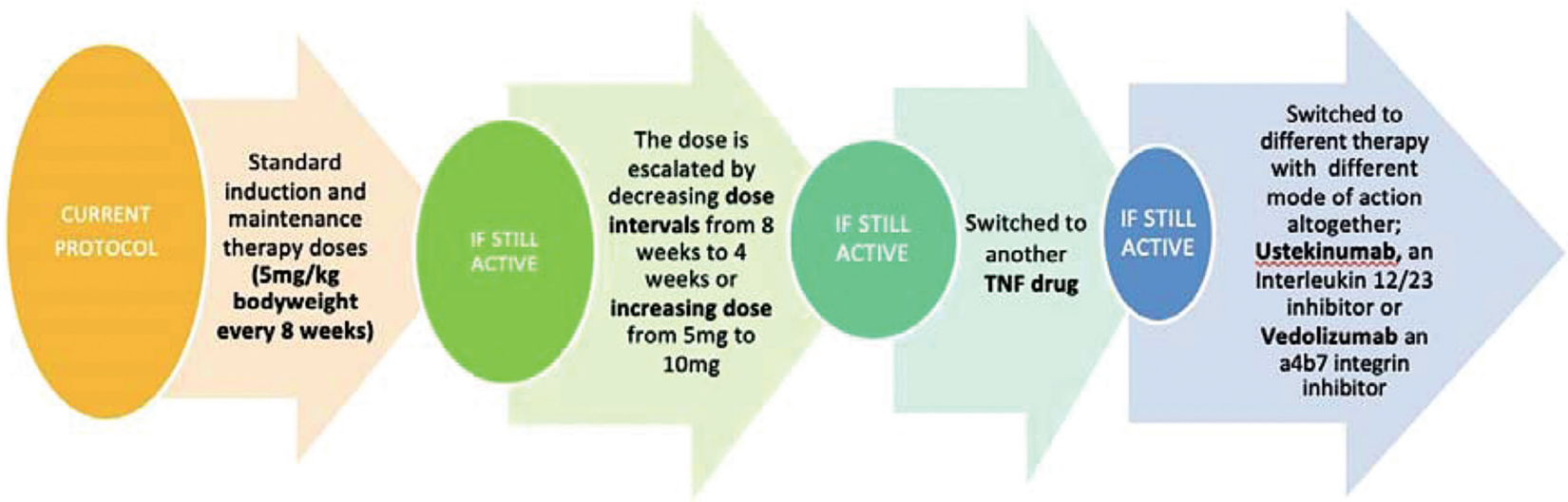

Fig 1. Therapeutic drug monitoring: current practice in the UK.

\section{Introduction}

Infliximab (IFX) is very effective in active inflammatory bowel disease (IBD) but up to nearly $50 \%{ }^{1}$ of patients will lose response or experience attenuated response to IFX due to fluctuating drug levels or formation of antibodies to IFX (ATI). There is growing evidence of the efficacy of therapeutic drug monitoring (TDM) ${ }^{2-4}$ Currently, the National Institute for Health and Care Excellence (NICE) does not recommend routine TDM in the NHS. Fig 1 shows current practice in the UK.

\section{Aims and methods}

Our primary objective was to assess the clinical and cost effectiveness of IFX TDM in IBD. We retrospectively analysed 122 IFX drug levels and 89 ATI levels of 85 patients (Table 1).

Patients were allocated to three groups based on the intent of TDM: maintenance group (MG) - proactive TDM on patients

Authors: ${ }^{A}$ Cardiff University School of Medicine, Cardiff, UK;

BUniversity Hospital Wales, Cardiff, UK with quiescent IBD, secondary loss of response group (SG) reactive TDM on active patients with established primary response to IFX, and post-induction group (PG) - TDM at week 14 post-induction. In each group, patient baseline characteristics were assessed to construct a global assessment of patient state (active, remission or responding to drug) prior and after TDM-led patient management for efficacy of IFX. Cost of IFX (Inflectra) was $\mathfrak{E} 123.50$ (+VAT) per $100 \mathrm{mg}$ while cost of TDM (IDKmonitor ELISA kit) was $£ 45$ per drug level assay and $\mathfrak{E} 45$ per ATI assay. Calculations were done comparing TDM with empirical IFX dose escalation and switching of drug.

\section{Results and discussion}

In MG ( $\mathrm{n}=51), 10$ (20\%) were de-escalated or stopped IFX and maintained in remission and 41 (80\%) IFX were continued. The mean IFX level was 1.89 vs $4.34 \mathrm{mg} / \mathrm{L}(\mathrm{p}=0.06)$, and mean ATI 85.10 vs $9.22 \mathrm{IU}(\mathrm{p}=0.0007)$, respectively in the two subgroups. The $20 \%(n=10)$ of patients were maintained in remission for a mean of 12.2 months (range 3-30 months) and were previously on IFX for a mean of 61.7 months (range 20-132 months). In the $80 \%$ of patients $(n=41)$, two became active after de-escalation, two became active despite having therapeutic IFX, 36 remained in remission and one patient's 
Table 1. Infliximab and antibodies to infliximab levels

\begin{tabular}{|c|c|}
\hline Total number of patients & 85 \\
\hline Age, mean, years (SD) & $39.13( \pm 14.25)$ \\
\hline Sex, male, n (\%) & $54(64)$ \\
\hline Weight, mean, kg (SD) & $76.13(15.54)$ \\
\hline Previous/current smoker, n (\%) & $25(29)$ \\
\hline Family history of IBD, n (\%) & $6(7)$ \\
\hline Crohn's disease, n (\%) & $62(73)$ \\
\hline Ulcerative colitis, n ( \%) & $23(27)$ \\
\hline Previous surgical treatment, $\mathrm{n}(\%)$ & $26(31)$ \\
\hline Stricturoplasty & $7(8)$ \\
\hline Subtotal colectomy & $5(6)$ \\
\hline Ileocaecal resection & $8(9)$ \\
\hline Fistula resection & $2(2)$ \\
\hline Small bowel resection & $3(4)$ \\
\hline Right hemicolectomy & $6(7)$ \\
\hline Abdominoperineal resection & $1(1)$ \\
\hline Emergency laparotomy & $2(2)$ \\
\hline \multicolumn{2}{|l|}{$\begin{array}{l}\text { Previous immunosuppressive drugs, } \\
\text { n (\%) }\end{array}$} \\
\hline Azathioprine & $79(93)$ \\
\hline Methotrexate & $18(21)$ \\
\hline Ciclosporin & $3(4)$ \\
\hline Adalimumab & $6(7)$ \\
\hline 6-mercaptapurine & $14(16)$ \\
\hline Tacrolimus & $1(1)$ \\
\hline $\begin{array}{l}\text { Combination therapy at the time } \\
\text { of drug level }\end{array}$ & $46(54)$ \\
\hline \multicolumn{2}{|l|}{$\begin{array}{l}\text { Number of drug levels done per } \\
\text { patient, } n\end{array}$} \\
\hline One & 57 \\
\hline Two & 22 \\
\hline Three & 3 \\
\hline Four & 3 \\
\hline \multicolumn{2}{|l|}{ Mean CRP at baseline, mg/L (SD) } \\
\hline Active $(n=69)$ & $14.03( \pm 21.39)$ \\
\hline Remission ( $n=53$ ) & $4.73( \pm 5.86)$ \\
\hline $\mathrm{p}$ value & 0.001 \\
\hline \multicolumn{2}{|l|}{$\begin{array}{l}\text { Mean haemoglobin at baseline, } \\
\text { g/L (SD) }\end{array}$} \\
\hline Active $(n=69)$ & $134.31( \pm 14.32)$ \\
\hline Remission ( $n=53$ ) & $140.56( \pm 13.24)$ \\
\hline $\mathrm{p}$ value & 0.007 \\
\hline
\end{tabular}

Table 1. Infliximab and antibodies to infliximab

levels (Continued)

\section{Mean calprotectin at baseline,} $\mathrm{pg} / \mathrm{g}(\mathrm{SD})$

Active $(n=69)$

$270.56( \pm 341.43)$

Remission $(n=53)$

$58.8( \pm 123.70)$

$p$ value

0.013

$\mathrm{CRP}=\mathrm{C}$-reactive protein; $\mathrm{IBD}=$ irritable bowel disease; $\mathrm{SD}=$ standard deviation.

status was unknown after stopping IFX (not included in cost savings calculation). Potential cost savings in MG were $\mathfrak{E} 669$ per person per year (17\% savings). In SG $(n=63), 21(33 \%)$ patients switched drug or had surgery post-TDM and in 42 (67\%) IFX dose was escalated or maintained. The mean IFX levels were 2.24 vs $3.48 \mathrm{mg} / \mathrm{L}$ ( $\mathrm{p}=0.19$ ), mean ATI 74.90 vs 10.29 IU $(p=0.0005)$ respectively in the two subgroups. Sixteen of 21 patients improved with change of drug (eight in remission, two active, three unknowns) showing a 76-90\% efficacy post-TDM. Twenty-eight of 42 from the IFX dose-escalated SG subgroup improved (12 in remission), 12 patients were still active and

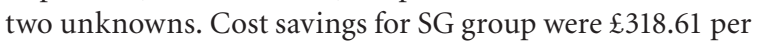
person (13\% savings). In PG, two of eight achieved remission and six of eight remained active and their mean IFX level was 2.2 vs $0.8 \mathrm{mg} / \mathrm{L}(\mathrm{p}=0.09)$ and mean ATI 0 vs $16.7 \mathrm{IU}(\mathrm{p}=0.22)$ respectively. Cost savings were $\mathfrak{E} 607$ per person in the PG group.

\section{Conclusion}

IFX TDM in IBD is clinically useful and has saved costs in all three patient groups, with the proactive TDM in post-induction and maintenance group benefiting the most.

\section{Conflicts of interest}

None declared.

\section{References}

1 Ding NS, Hart A, De Cruz P. Systematic review: predicting and optimising response to anti-TNF in Crohn's disease - algorithm for practical management. Aliment Pharmacol Ther 2016;43:30-51.

2 Steenholdt C, Bendtzen K, Brynskov J, Ainsworth MA. Optimizing treatment with TNF inhibitors in inflammatory bowel disease by monitoring drug levels and antidrug antibodies. Inflamm Bowel Dis 2016;22:1999-2015.

3 Feuerstein JD, Nguyen GC, Kupfer SS et al. American Gastroenterological Association institute guideline on therapeutic drug monitoring in inflammatory bowel disease. Gastroenterology 2017;153:827-34.

4 Vande Casteele N, Ferrante M, Van Assche G et al. Trough concentrations of infliximab guide dosing for patients with inflammatory bowel disease. Gastroenterology 2015;148:1320-9.e3. 